\title{
Impact of Music on Sport Intensity (Allegro) and on Levels of Left Ventricular Myocardial Damage in Wistar Rats
}

\author{
Faris Pamungkas Wicaksono ${ }^{1}$, Sugiharto ${ }^{2}$, Rias Gesang Kinanti² ${ }^{2}$ Paulus Liben ${ }^{3}$, \\ Suhartono Taat Putra ${ }^{4}$ and Purwo Sri Rejeki ${ }^{3}$ \\ ${ }^{1}$ Master of Sport and Health Science, Universitas Airlangga, Surabaya, Indonesia \\ ${ }^{2}$ Faculty of Sport Science, Universitas Negeri Malang, Malang, Indonesia \\ ${ }^{3}$ Department of Physiology, Faculty of Medicine, Universitas Airlangga, Surabaya, Indonesia \\ ${ }^{4}$ Department of Pathology, Faculty of Medicine, Universitas Airlangga Surabaya, Indonesia \\ apji@fk.unair.ac.id
}

Keywords: Music, sports, myocardiocyte, left ventricle

\begin{abstract}
Music with exercise could improve left ventricular performance, thereby decreasing the extent of tissue damage in the left ventricle of the heart. The study aimed to measure sports intervention with fast tempo music (Allegro) on the extent of cellular damage to the left ventricular myocardial tissue of the heart. This study used an experimental research design using a Random Controlled Group Posttest-Only Design. A control group was played Allegro music, a moderate sports group was played Allegro music, and a highintensity sports group was played Allegro music using Wistar white rats of the male sex. Sport was performed using a special treadmill for mice for ten weeks. Data analysis was performed using ANOVA test. The results of this study show that there was a difference in left ventricular wall thickness in the heart between the control group and allegro music group, moderate exercise group with allegro music, and highintensity group with allegro music $(\mathrm{F}=19,636 ; \mathrm{p}=0.001)$. This study showed that high-intensity exercise with allegro music has the potential to improve the health of the left ventricle of the heart.
\end{abstract}

\section{BACKGROUND}

Heart disease ranks first as the 10 most common diseases according to WHO data in 2008. The cause of death in 17 million people was $43.3 \%$ by heart disease (Kay and Santos, 2008). The cause is lack of physical activity and sports (Agarwal, 2012). Exercise can improve cardiac function, quality of life, reduce the risk of heart disease and improve physical function (Hordern et al., 2012). However, poorly managed sport creates an increased risk of stress resulting in lower quality of health and may lead to an increase in heart attack, both stimulant and responsive (Uchakin, 2003). Arrhythmias may be caused by excessive exercise, not only in untrained individuals but also in trained individuals such as athletes. Arrhythmias may occur in professional athletes due to excessive exercise doses resulting in overtraining. Excessive exercise can have an impact on the deterioration of health and achievement. Heart disease causes problems and needs to be revealed. So there will be no ambiguous opinion between sports with heart disease problems (Pepe et al., 2013).

Exercise will produce a good physical condition. Excessive exercise and improper doses can lead to an increase in blood pressure. Excessive blood pressure during exercise may result in the addition of a parallel sarcoma, so dilated cells occur that increase left ventricular wall thickness without reducing the size of the deep cavity at the time of diastole with left ventricular concentric development in hypertrophy (Fernandes et al, 2011). This results in fatigue that triggers an increase in stress hormones in high competition situations (Hackney, 2006). The high stress of competition can cause physical, physiological and psychological stress (Uchakin, 2003), resulting in early symptoms of arrhythmias and triggering hypertension, ischemia, and heart attacks leading to death. Necrosis of cells that die from an acute injury are usually swollen and ruptured by the loss of membrane integrity (Guyton, 2007). Active cells will continuously adjust cell structure

Pamungkas Wicaksono, F., Sugiharto, ., Gesang Kinanti, R., Liben, P., Taat Putra, S. and Sri Rejeki, P. Impact of Music on Sport Intensity (Allegro) and on Levels of Left Ventricular Myocardial Damage in Wistar Rats. In Proceedings of Surabaya International Physiology Seminar (SIPS 2017), pages 378-382 ISBN: 978-989-758-340-7

Copyright $\odot 2018$ by SCITEPRESS - Science and Technology Publications, Lda. All rights reserved 
and function to accommodate change and suppress extracellular impact. This is usually depend on intracellular homeostasis. During ischemia during exercise, there is a decrease in oxygen and ATP levels in the cells (Araujo et al., 2014).

The body responds to exciting and fun sport. Highintensity exercise will activate Hypothalamic-PituitaryAdrenal (HPA) axis and Sympathy Adrenal Module (SAM) (Usui et al., 2011). So, when exercising, the heart will respond and the rest are determined by the autonomic nerves. Exercise is performed through two mechanisms, namely the central nervous and autonomic nerves. Central nerves cause changes in the sympathetic nerves and parasympathetic nerves (Sugiharto, 2014). Increased sympathetic nerve stimuli lead to high norepinephrine, resulting in increased cardiac output and stress affecting the systemic lungs, liver, lymph, and heart muscle activation. However, exercise with pleasure and joy will decrease stress so that the work of the HPA axis is inhibited. Increased exercise intensity leads to increased HPA axis work that increases the hormone cortisol while affecting the activity of glucocorticoids and corticosteroids, which cause resistance to insulin receptors, The Hypothalamic-Hypophysis-Adrenal (HHA) axis decreases immunity to disease and increases incidence of heart disease (Liu et al., 2000). Exercise should be well managed, not just the right dose of exercise, but it should also provide a sense of fun. Listening to music tends to give a sense of fun to enjoy sport (Lin et al., 2011).

Exercise is able to reduce stressors by listening to music. Music that is heard during exercise changes the stressor into a stimulator through a coping mechanism. Exercise while listening to loud music can increase the heart rate higher than by doing sport and listening to slow music (Sugiharto, 2014). This is because music can divert attention from fatigue when listening to music based on the right choice so as to improve body performance (Sabaghian, 2013). In addition, music can reduce the risk of stress, anxiety levels, and increase the pleasure caused by a decrease in plasma norepinephrine and cortisol (Uedo et al., 2004). So music can be a stimulator that is able to create a good homeostasis for the body. However, sports with music can also be risky if excessive or inappropriate exercise dosing is given.

On the basis of this background, the researchers aimed to prove that sports intervention with fast tempo music (Allegro) affects the damage level of myocardiocytes of the left ventricle of the heart in Wistar rats.

\section{METHODS}

Experimental research with a Randomized Controlled Group Posttest-Only Design was conducted with three groups: moderate group with allegro music, high-intensity group with allegro music, non-sports control group with allegro music, and random sampling using a "matching" technique (Sugiharto, 2006). This study used 24 rats with each group divided into eight rats. The study was conducted using healthy, 6-7-month-old Rattus norvegicus Strain Wistar rats weighing 300-350 grams. The animals were exercised on a modified treadmill of mice three times a week, 900-4,100 seconds, 3-6 sets, 6-10 repetitions, for 10 weeks, using a high intensity with a speed of $22-25$ meters/min $(80 \%$ VO2Max) and moderate intensity speed of 14-16 meters/minute (65-70\% VO2Max) (Kim et al., 2013), starting at $05.00 \mathrm{pm}$ until completion. The animal examination procedure using the Hematoxylin-Eosin (HE) staining method and left ventricular myocardiocyte measurement was applied along with the histology quantitative analysis method on a Microscope Olympus BX 51 and OlyVIA data software, which can be used if using Microsoft Excel in the Pathology Laboratory of the Faculty of Medicine Universitas Brawijaya Malang. All data were tested using the Packet for Social Science (SPSS 16.0) application. Maintenance of animal experiment subject was located in lecture building of Nursing and Midwifery, Universitas Brawijaya.

\section{RESULTS}

The results of the research are shown in Figure 1.

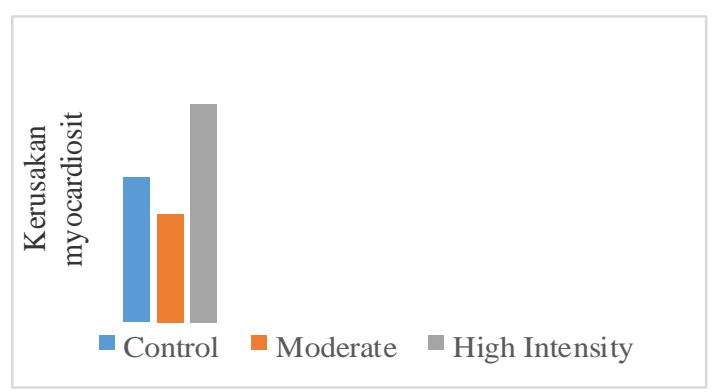


Figure1: The mean of damage to the Myocardiocyte Treatment Group.

Table 1: Homogeneity Test of Data Damage to Myocardiocytes of the Left Ventricle of the Heart.

\begin{tabular}{cccc}
\hline $\begin{array}{c}\text { Levene } \\
\text { Statistic }\end{array}$ & df1 & df2 & Sig. \\
\hline 11.512 & 2 & 20 & 0.100 \\
\hline
\end{tabular}

Based on the homogeneity test results (Table 1) the left ventricle of the heart was homogeneous because (Sig. $>$ A, with $\alpha=0.01$ ), and then the test was continued with the ANOVA test.

Table 2: Anova Differential Test of Damage to Myocardiocytes in the Left Ventricle of the Heart.

\begin{tabular}{lcr}
\hline & F & Sig. \\
\hline Between Groups & 19.636 & 0.001 \\
Within Groups & & \\
Total & & \\
\hline
\end{tabular}

Based on the different Anova test there was a significant difference between the moderate intensity exercise group, high-intensity exercise group, and control group with allegro music with regard to left ventricular myocardiocyte damage $(\mathrm{P}<0.05$, with $\mathrm{P}=$ $0.001)$.

\section{DISCUSSION}

The high cell damage in the left ventricle of the heart in high-intensity sports with allegro music was directly proportional to the thickness of the ventricle. So, the possibility of damage resulting from the effects of highintensity exercise does not equate to a decline in heart function because of the high damage to myocardiocytes increases the remodeling of heart cells in the left ventricle with remodeling that replaces the new cells which increases the work of the heart. Cell necrosis is cell death from acute lesions which are usually swollen and broken due to loss of membrane integrity (Guyton, 2007). The active cells will continuously adjust cell structure and function to accommodate change and suppress extracellular impact. This is usually depend on intracellular homeostasis. As cells experience physiological suppression or pathological stimulation, they undergo adaptation, achieve new conditions, and maintain cell survival and function. The main responses are hypertrophy, hyperplasia, atrophy, and metaplasia. During ischemia, while exercising, there is a decrease in oxygen and ATP levels in the cells. This decrease is associated with increased cellular oxidant production, excessive calcium ions $(\mathrm{Ca} 2+)$, elevated levels of hydrogen ions $(\mathrm{H})$, and calcium activation with protease calpain. In early reperfusion, there is acute excess cellular calcium and the production of oxidants in the heart muscle. Collectively, increased levels of calcium and oxidants promoting calpain and caspase-3 activation contribute to cellular injury, which can lead to cell death. Ischemia contributes to cellular injury and cell death from necrosis and apoptosis. The higher heart response due to high-intensity exercise triggers high levels of proliferating cell nuclear antigen (PCNA) proteins indicated by cardiac remodeling or heart growth that increases the incidence of cardiac myocyte hyperplasia while elevated levels of heart mRNA, Myocyte Enhancer Factor MEF2C, GATA4, and ACTA1 increase the hypertrophy of cardiac myocytes (Alonso-Montes et al., 2008). High-intensity exercise without the use of music causes damage, but such damage has the potential to improve cardiac performance (Cassidy et al., 2016). Remodeling occurs after 1-5 minutes of ischemia, resulting in fibrillation without cell death in ventricular contraction performance, and ischemic and remodeling rates are at the highest when ischemic occured over 20 minutes exercise (Powers et al., 2008). High-intensity exercise will improve Cyclic Adenosine Monophosphate (cAMP). Protein Kinase A (PKA) send signal toward target proteins such as L-Type Ca Chanel (LTCC) to Sarcoplasmic Reticulum (SR) which plays a phospolamban role for contraction of Troponin $\mathrm{C}$, I and $\mathrm{T}$. In addition, it also binds ions to increase heart rate (Gordan et al., 2016). Heart rate increased will trigger blood pressure and cause parallel sarcomeres increased, resulting in widened cells that result in increased left ventricular wall thickness without reducing organ size at the time of diastole with left concentric development resulting in hypertrophy (Fernandes et al., 2011).

Music affects the contraction of the heart, and this depends on the type of music being heard. Previous research has shown that exercise with fast music increases the heart rate compared with slow music (Sugiharto, 2014). Likewise, other studies have proven that exercise accompany by music will stimulate central nervous system and autonomic nerves, health, emotional, and physiological adaptations that reduce the stress caused by exercise (Perez-Lloret et al., 2014). Basically, exercise is a stressful condition which 
the body responds to by activating the cardiorespiratory system, the locus ceruleus (LC/norepinephrine (NE), metabolic system and HPA axis system. Sport stress activates the SAM axis to secrete catecholamines, thus increasing heart function during exercise (Mastorakos et al., 2005). High-intensity exercise with music accompaniment improves heart function. The functional heart load imposed by exercise can increase the stimulation of heart cell changes such as hypertrophy and normalize pressure according to the Laplace law (Iwado et al., 2003).

\section{CONCLUSIONS}

Based on the results it can be concluded that sport with music helps increase cell division to improve heart function. The higher the functional load of the heart as the sport intensity increases, the more new cells will grow. The growth of new cells is called hyperplasia, but hypertrophy also occurs in inflamed cells. Damage to myocardiocytes is a natural process and the higher the workout the better the heart function. This study suggests that exercise should be accompanied by music as it is proven to improve cardiac function. So, sports and music should be well managed in regard to sports load, intensity, and duration of exercise.

\section{REFERENCES}

Agarwal, S. K. (2012). Physical Activity And Cardiovascular Diseases Abrief Revie. Int J Gen Med, 5, 541-545.

Alonso-Montes, C., Castro, M. G., Reguero, J. R., Perrot, A., Ozcelik, C., Geier, C., . . Coto, E. (2008). Mitochondrial transcription factors TFA, TFB1 and TFB2: a search for DNA variants/haplotypes and the risk ofjj cardiac hypertrophy. Dis Markers, 25(3), 131-139.

Araujo, A. C., Santos, B. F., Calasans, F. R., Pinto, I. M., Oliveira, D. P., Melo, L. D., . . Oliveira, J. L. (2014). Physical Stress Echocardiography: Prediction of Mortality and Cardiac Events in Patients with Exercise Test showing Ischemia. Arq Bras Cardiol, 103(5), 418425.

Cassidy, S., Thoma, C., Hallsworth, K., Parikh, J., Hollingsworth, K. G., Taylor, R., . . . Trenell, M. I. (2016). High intensity intermittent exercise improves cardiac structure and function and reduces liver fat in patients with type 2 diabetes: a randomised controlled trial. Diabetologia, 59(1), 56-66. doi: 10.1007/s00125015-3741-2

Fernandes, T., Soci, U. P., \& Oliveira, E. M. (2011). Eccentric and concentric cardiac hypertrophy induced by exercise training: microRNAs and molecular determinants. Braz J Med Biol Res, 44(9), 836-847.
Gordan, R., Fefelova, N., Gwathmey, J. K., \& Xie, L. H. (2016). Involvement of mitochondrial permeability transition pore (mPTP) in cardiac arrhythmias: Evidence from cyclophilin D knockout mice. Cell Calcium, 60(6), 363-372. doi: 10.1016/j.ceca.2016.09.001

Guyton, A. C. H., J.E. . (2007). Textbook of medical physiology (11th ed.). Philadelphia, Pennsylvania: Elsevier Saunder.

Hackney, A. C. (2006). Stress and the neuroendocrine system: the role of exercise as a stressor and modifier of stress. Expert Rev Endocrinol Metab, 1(6), 783-792. doi: 10.1586/17446651.1.6.783

Hordern, M. D., Dunstan, D. W., Prins, J. B., Baker, M. K., Singh, M. A., \& Coombes, J. S. (2012). Exercise prescription for patients with type 2 diabetes and pre-diabetes: a position statement from Exercise and Sport Science Australia. J Sci Med Sport, 15(1), 25-31. doi: 10.1016/j.jsams.2011.04.005

Iwado, Y., Furuyama, H., Yoshinaga, K., Mabuchi, M., Ito, Y., Noriyasu, K., . . . Tamaki, N. (2003). Transient left ventricular dysfunction in ischaemic myocardium after stress: comparative study with exercise and pharmacological stress gated myocardial single photon emission computed tomography. Nucl Med Commun, 24(5), 551-557. doi: 10.1097/01.mnh.0000071250.54690.93

Kay, M., \& Santos, J. (2008). Report on the World Health Organization Global Observatory for eHealth strategic planning workshop, April 2008. Methods Inf Med, 47(4), 381-387.

Lin, M. F., Hsieh, Y. J., Hsu, Y. Y., Fetzer, S., \& Hsu, M. C. (2011). A randomised controlled trial of the effect of music therapy and verbal relaxation on chemotherapy-induced anxiety. J Clin Nurs, 20(78), 988-999. doi: $10.1111 / \mathrm{j} .1365-$ 2702.2010.03525.x

Liu, J., Yeo, H. C., Overvik-Douki, E., Hagen, T., Doniger, S. J., Chyu, D. W., . . . Ames, B. N. (2000). Chronically and acutely exercised rats: biomarkers of oxidative stress and endogenous antioxidants. J Appl Physiol (1985), 89(1), 21-28. doi: 10.1152/jappl.2000.89.1.21

Mastorakos, G., Pavlatou, M., Diamanti-Kandarakis, E., \& Chrousos, G. P. (2005). Exercise and the stress system. Hormones (Athens), 4(2), 73-89.

Pepe, J., Curione, M., Morelli, S., Colotto, M., Varrenti, M., Castro, C., . . . Minisola, S. (2013). Arrhythmias in primary hyperparathyroidism evaluated by exercise test. Eur J Clin Invest, 43(2), 208-214. doi: 10.1111/eci.12038

Perez-Lloret, S., Diez, J., Dome, M. N., Delvenne, A. A., Braidot, N., Cardinali, D. P., \& Vigo, D. E. (2014). Effects of different "relaxing" music styles on the autonomic nervous system. Noise Health, 16(72), 279-284. doi: 10.4103/1463-1741.140507

Powers, S. K., Quindry, J. C., \& Kavazis, A. N. (2008). Exercise-induced cardioprotection against myocardial ischemia-reperfusion injury. Free 
Radic Biol Med, 44(2), 193-201. doi: 10.1016/j.freeradbiomed.2007.02.006

Sabaghian R. L., a. H. (2013). The effect of motivational music during exercise on the performance of elite female swimmers. European Journal of Experimental Biology, $3(3), 106-110$.

Sugiharto. (2006). The Effects Of Exercise Response On Creatine Kinase In White Wistar Rats Folia Medica Indonesiana, 42(4), 228-232.

Sugiharto. (2014). Fisiologi Olahraga: Teori Dan Aplikasi Pembinaan Olahraga. Malang: Universitas Negeri Malang Press.
Uchakin, P. N., Gotovtseva, E. P. and Stray-gundersen, J. (2003). Immune and Neuroendocrine Alterations in Marathon Runners. 3(4), 483-494.

Uedo, N., Ishikawa, H., Morimoto, K., Ishihara, R., Narahara, H., Akedo, I., . . . Fukuda, S. (2004). Reduction in salivary cortisol level by music therapy during colonoscopic examination. Hepatogastroenterology, 51(56), 451-453.

Usui, S., Maejima, Y., Pain, J., Hong, C., Cho, J., Park, J. Y., . . . Sadoshima, J. (2011). Endogenous muscle atrophy F-box mediates pressure overloadinduced cardiac hypertrophy through regulation of nuclear factor-kappaB. Circ Res, 109(2), 161-171. doi: 10.1161/CIRCRESAHA.110.238717 